\title{
Employing a multifocal view of ECD curriculum development at a rural settlement community in South Africa: Themes from a 'design by implementation' early childhood education programme
}

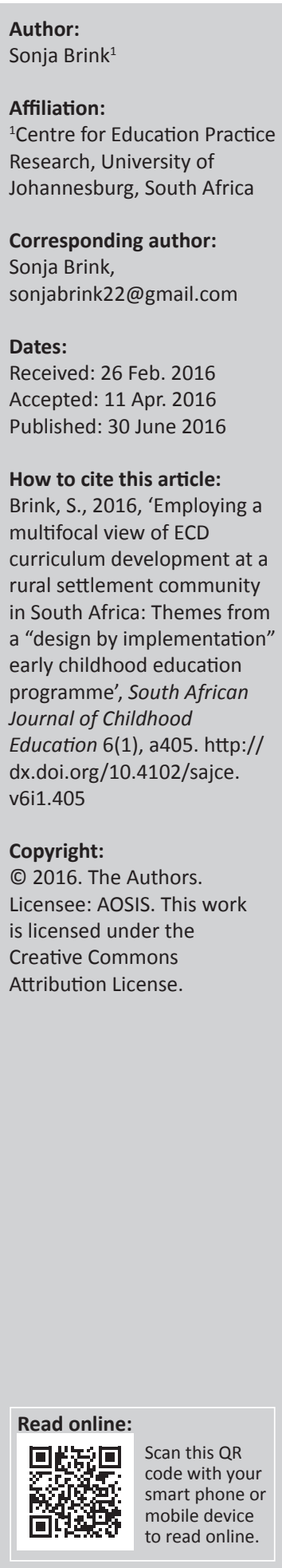

Early childhood curriculum development is challenged by the vast contextual variability of sites in South Africa. In this article, the author reports on the implementation of an early childhood development programme at an informal rural settlement community by an external societal agent. The article looks at the complex dynamics at play within such an early education development situation and examines the main themes that emerged from the process. Referring to the tensions that emanated from the implementation of this programme as a positive driver for change, it concludes that the employment of participatory methodologies could be utilised as a curriculum development tool and calls for the employment of a less formulaic and more holistic view of early childhood development.

\section{Introduction: Curriculum development in South Africa - by practice or by precept?}

Early childhood development and education programmes, as means to help close the performance gaps between children from different social and economic backgrounds in developing countries, have been increasingly on the forefront of South African education agenda in recent years (Biersteker \& Dawes 2008; Department of Basic Education 2011; 2013). Several factors such as poverty, HIV and/or AIDS, and poor healthcare impact negatively on the lives of more than half of South African children, adversely affecting their ability to effectively access healthcare and education (Atmore, van Niekerk \& Ashley-Cooper 2012). It is well recognised that the relevant authorities aim to actively mobilise around these issues. One of the most prominent focus areas identified as a way to help ameliorate these deleterious factors impacting on young children's lives is through the provisioning of quality early childhood development programmes (Human Science Research Council \& Early Learning Resource Unit 2010).

In South Africa, more than 13 million children live in poverty (Children's Institute 2012). The link between poverty and issues such as poor health, inadequate nutrition, reduced access to healthcare and education is well documented (see Aliber 2003; Atmore et al. 2012; Biersteker 2001). Children in rural areas are often hardest hit by these distressing factors. Of the approximately 8.5 million children living in rural areas in South Africa, $67 \%$ are in the poorest quintile (Children's Institute 2012). Negative factors that afflict education delivery in rural areas include lack of infrastructure, low employment rates, low education and skills levels and the effects of HIV/AIDS on the lives of children living in rural areas (Dearing, Berry \& Zaslow 2006; Grey 2008).

The need for the development of quality ECD programmes and for increased access to such programmes is well recognised by the relevant departments of Social Development, Health and Education. ECD was also included in the Human Resources Development Report for the first time in 2008. According to Biersteker and Dawes (2008), the authors of the chapter on ECD in that document, this indicates the extent to which the South African government has realised how important ECD is for laying the foundation for success in the schooling system and how important it is to introduce especially those children who come from poverty environments to quality ECD provisioning. Significant progress has been made over the past 12 years to enhance early childhood development in the country. Examples of these are: The establishment of formal structures concerned with the sector, within relevant departments; free healthcare for pregnant women and children from birth to 6 years; increased expenditure in the form of child grants and also money earmarked specifically as subsidies to ECD sites; and the introduction of grade $\mathrm{R}$ and the formal documentation 
of aspects of early childhood development such as The Children's Act (Atmore et al. 2012).

Several models of early childhood development approaches have emerged during the past two centuries and are still being followed across the world (Anderson et al. 2003; Edwards 2002), and principles of many of these could be, and have been, applied in varying degrees towards the development of ECD programmes in South Africa. Exactly which components of early childhood interventions would be the best to include for optimal effect within developing contexts, and for what reason, is unclear from an analysis of international evidence of the benefits of 30 early childhood interventions in 23 non-US countries (Nores \& Barnett 2009). Another study, aimed at analysing the findings of 40 studies representing 28 different ECE programmes, noted two characteristics of those programmes reviewed (Chambers et al. 2010). The first was a clear cognitive or academic focus, which was noted as giving 'structure and objective content to guide the educators' work in the classroom' (p. 38). The second pertains to educator training - extensive training, with intensive support and regular 'follow-up coaching by the development or researcher' (2010). In their review of the literature on early childhood education which aims to assess the impact of various programmes and their suitability to the Madagascan context, Loomis and Akkari (2014) find that determining which of the huge diversity of preschool programmes, with their vast variations in philosophical, organisational and pedagogical foci, is not easy, and that in the final analysis, the impact of any specific curriculum is affected by local dynamics and should therefore be closely related to the home and community environment within which young children grow up.

I propose that the idea of a curriculum that would serve all the children of South Africa equally - especially those children who are at risk of performing poorly in their school careers - is challenged by the question of how to create a curriculum plan that would be applicable to all contexts within which children in South Africa grow up. For example, the social, physical and political dynamics that operate within larger, more urban groups of people vary substantially from those that hold sway in smaller, rural settlement communities and indeed, in such smaller communities of people, the implementation of a generic ECD curriculum could very well amount to nothing more than a societal construct being superimposed upon a people who have no use for it in their everyday situation.

I want to argue, therefore, that an effective ECD curriculum does not depend so much on its content, but for it to truly help narrow the inequalities left by apartheid and the lack of focus, until recently, on ECD as the foundation of a child's further career, it would have to be densely context bound to serve all the children in South Africa effectively. As I will show in this article, which will highlight the main themes that emerged from research on the process of developing an early childhood development programme within a rural informal settlement community, there might be powerful dynamics affecting the design and implementation of an ECD programme at such a site.
This article will investigate how perceptions of scarcity and lack of resources together with the perceived power held by certain individuals, groups and formal and informal power structures within a resource-poor rural community might hinder important role players from taking part in and from taking ownership of the early childhood education process in their community. Furthermore, it will have a look at how educational concepts such as 'teaching' 'education' and 'school' might be conceptualised differently by parents and educators in rural areas from how these terms are used elsewhere and in Western education literature (Van der Vyver 2012). Also, it will examine how variants in the views of different stakeholders in the implementation of a rural settlement ECD programme might play a significant role in how effectively early childhood education is delivered at that site. For example, local and traditional views on, and values around, childcare and early education might differ radically from those of the societal agents designing and implementing the curriculum (Pence \& Marfo 2008). Furthermore, it will examine the challenges which teachers and educators at rural sites face in terms of physical and knowledge resources to help them teach and they might, in the execution of their duties as educators, have to abide by local rules and traditions, some of which might not necessarily be aligned with the tenets of a one-size-fits-all curriculum. Finally, it will explore how participatory action research (PAR) can be applied as an effective curriculum development tool to generate a context-specific early childhood programme tailor-made for this rural community.

ECD curriculum development and implementation at informal rural sites is a complex and often challenging process made up of an interdependent matrix of circumstances, relationships and role players. This interplay between aspects of externally initiated early childhood education provisioning and the dynamics operant within the community frequently causes tensions. These tensions, if not managed effectively, could diminish the possible benefits of ECD delivery for the community (Van der Vyver 2012). However, if managed properly, I propose that they can be powerful mechanisms for change (2012). Towards a better understanding of the contextual complexities arising from such a dynamic, I will thus describe the main themes that emerged during research that was conducted during the 'organic' (Henning [University of Johannesburg] pers. comm., 16 October 2010) process of establishing an ECD curriculum, in PAR mode, at a rural site where I was at the same time development practitioner and participant researcher. An 'organic' process of curriculum development means that the programme is allowed to evolve in situ, naturally, over time, and according to the specific dynamics at the site - with the input of the local community for which the programme is intended and without the planners and implementers insisting on a pedantic adherence to the initial curriculum plan. I will now outline the research design and methodology that was used in this research project and then continue with the background to the establishment of the preschool at Mogwase, after which I will highlight the main themes that emerged during the process and discuss the 
participatory methodology that was employed in this education development project of which I was, at the time, project manager.

\section{Research design and methodology}

The purpose of this inquiry was to find practical solutions to a practical problem in the real world. This inquiry is about development practice and the development of a contextspecific curriculum through the empowerment of lay teachers and semi-literate parents to eventually be capable of taking ownership of the preschool in their community. It was the very tension between the need for a better outcome to the problems they faced and finding better ways to bring about transformation that directed the design and methodology for this purpose-driven study.

This research took place within the ECD component of a larger community development programme in which the community development practitioners followed a collaborative approach to development which encourages dialogue that fosters a continuous learning orientation in order for the community to become more aware of its own needs, and to make decisions about those needs and thus be able to adapt to changing situations (Foster-Fishman et al. 2001). These collaborative processes include planning, community action and change, adaptation to new circumstances, thinking in new ways and exploring different pathways to overcome obstacles.

Cycles of planning, implementing and reflecting, the lessons learnt during the pre-design phase of this study, clearly lead the participants and the researcher towards PAR. It can be argued that the events which came about as a result of the larger community development project, and which preceded the formal research, predisposed PAR as research methodology for this study. Thus, the formal part of the research design was created, not in a void, but after several cycles of planning, action and reflection at the onset of the implementation of the ECD programme. The first formal planning cycle of this PAR study - the formulation of the research questions - therefore needs to be seen, not only as the starting point of the research but also as a subsequent cycle 'flowing from' the preceding cycles of planning, action and reflection. The point at which the research questions were formulated is therefore, in this case, at the same time the start of the formal part of the research and also already a redefining of the intervention.

The unit of analysis in this study is the ECD practitioner-intraining in the context of concomitant ECD curriculum development. The construct of 'teacher development' was operationalised into real, observable phenomenon such as 'teachers who talk about their work at the crèche; teachers who worry about aspects of their work; teachers who perceive their world in a certain way', and so on. The construct of 'curriculum development' was examined through recording and observing of how the role players in the curriculum; the teachers, trainers, parents, leaders and other stakeholders experienced it, talked about it and how they perceived their own role in its development.

Sampling was by way of purposeful selection of the intact group that constitutes the case. Included in this are the key participants in the community: the ECD trainers, the ECD teachers-in-training, the community development practitioners, the community leader and community steering committee members. These groups were direct samples and each was chosen because it would provide data that would help to address the research questions. Using multiple data sources in a case study research design is in alignment with the principle that a situation be experienced and described from multiple perspectives.

Ten different data sources were analysed for this study, some of which, such as the minutes of meetings, the development practitioner's notes, social worker's reports and project documentation, already existed as documents which formed part of the community development project at the time. Upon analysing these and converting them to formal 'sets', they became part of the PAR inquiry as documents and were thus analysed in document analysis mode. To a certain extent, information was thus morphed from field knowledge sources in everyday discourse, to systematic social science knowledge.

Two collections of teachers' awareness reports were designed at different points during the pre-research phase. These two sets of data, together with the teacher trainer's diary, informed the design of a purposefully designed interview schedule which was administered to the teachers. To a certain extent, the minutes of the meetings informed the design of the interview with the parents and the community leader as a way to see how perceptions about the preschool had changed within the community. It is important to note that as researcher I decided to use field notes made as development practitioner sparingly and only to confirm other analysis outcomes, as I was wary of letting my voice as development practitioner dominate those of the more important role players, such as the teachers and the members of the community. Likewise, the project documentation and the informal discussions with the social worker were used only to confirm analysis outcomes of the other data sets.

\section{Background to the preschool at Mogwase}

A community member from Mogwase stated the following:

'This is not just a crèche - it is a place of light where everyone comes to learn.' (2012)

Mogwase is a small rural settlement, with a population of approximately 750 people, on the border between Gauteng and the North West province. Here, in 2010, the establishment of an externally funded ECD centre gave rise to the research from which emanated the themes that will be discussed in this article.

The idea for the establishment of a preschool as an extension of a larger community development project was suggested 
by the external corporate funding agent at a point in time when the community had not yet expressed any need for such an intervention. Although the social development agents, who, by then, had been involved in development work at the settlement for longer than a year had, up until then, been following a collaborative model of community development, which rests on the assumption that people should control their own lives by means of political equality and popular sovereignty (Summers 1986), they did not want the community to pass up on such a generous offer and thus embarked on an awareness campaign to make the people of the settlement aware of the importance of early childhood development and of the benefits that the donation of the centre would hold for them. Because, by then, a relationship of mutual trust had been established between the people of the settlement and the social development agents, the community did not take a long time to decide that the implementation of the proposed ECD centre and programme could go ahead.

Despite the excitement of the community members at being the recipients of an envisaged means to the provision of more formal early childhood care and education to their children, their engagement in the process soon sparked tensions that, were it not for a commitment by all to participatory methodologies, could easily have ruined the process of establishing this facility in the community.

It was decided that instead of importing trained ECD practitioners from outside of the village to work at the centre, young mothers from the community would be trained to become ECD practitioners, thus enhancing the human resources and knowledge capital of the settlement. Furthermore, a strategy was conceived by which, instead of providing the volunteer teachers with formal training and scripted lesson plans, they would be left to find out for themselves what works best for them. This, it was envisaged, would happen through their applying their indigenous knowledge of early childhood care and education to the new education situation which they formed a part of. This plan of action, suggested by the development practitioners and agreed upon by the leadership structures within the community, started a process of actions and reactions that often became fraught with tension and that demanded increasing levels of equal engagement by all role players; development agents, volunteer teachers, parents and community leaders. After it became clear that the teachers were floundering in their efforts to establish a programme at the centre, and that their perception of ECD delivery did not satisfy the expectations of the parents, it was decided that an external 'teacher trainer' would be solicited to guide and train the teachers, more formally, in aspects of early childhood development and education and to help them develop a programme. A teacher trainer was appointed and thus began a process of curriculum development that would require the engagement of all stakeholders in the intervention.

Several factors impacted upon the development of the ECD programme at this site. Gazing back, in PAR mode, it becomes abundantly clear that it was only because issues were allowed to be talked over and their effects played out by everyone concerned, and often in a rather entropic way, that a working curriculum for Mogwase was forged, and is still being developed at present. In the next section, I will discuss the main themes that emanated from this research and then shortly explain the participatory methodology that was employed as curriculum development tool in the case.

\section{Societal intentions - local understanding}

According to a volunteer teacher from Mogwase the:

The crèche is important - it is the place where the children are looked after. It helps keep the children safe, out of the wetland area. (2010)

Although over $90 \%$ of children in the world live outside of the Euro-Western world, the vast majority of the body of literature on ECD still derives from a Western worldview and is by and large generated by authors from developed countries, especially the United States (Pence \& Marfo 2008). A more appropriate and culturally sensitive way of ECD delivery would need to come about through what these authors term a 'co-constructed generative curriculum approach' (2008:6), which would retain those aspects from imported models which have utility value within the given context and integrate these into existing indigenous knowledge systems of early childcare and education. This means that interaction and dialogue between all the different role players is encouraged instead of a strict adherence to a preset directive of how ECD should be implemented. It also takes into account different aspects, such as local child development customs and knowledge systems, and blends these with those aspects of the Western education tradition which prove to have utility value at that site. From the resultant dynamic, and the emphasis is here on dynamic, the most effective way of going about the development of ECD is then 'co-constructed' and an appropriate-for-that-site curriculum thus 'generated'.

In a South African compilation titled 'The black child in crisis', published before early childhood development was formalised as a focus of education in South Africa, Atmore (1994, in Le Roux 1994:157) proposed that early childhood curricula should be closely aligned with the culture and identity of the child's community while at the same time preparing the child for participation and integration into a wider, more diverse community. Such articulation between curriculum and context is, according to Nsamenang (2007), sorely lacking from reports such as the EFA Global Monitoring Reports $(2006$; 2007) which, this author contends, do not contain practical guidelines for handling contextual difficulties and certainly do not fully grasp the realities of resource-poor countries that have to rely on international agencies who train according to Euro-American norms and with no regard for ethnical and cultural realities.

The physical well-being and safe keeping of young children was one of the main expectations of the function of the centre 
in the early days of the ECD programme at Mogwase. In contrast to the expectations of the external agents who viewed the ECD programme and its projected outcomes mainly in terms of education, the role of the centre and the teachers was seen by the community, at least initially, as that of taking care of the physical well-being of the children. In other words, the crèche was there, mainly, to keep the children safe and to feed them twice a day. Although physical safety is of course important at any early childhood development site, in a settlement situated far from medical help or healthcare, this aspect of childcare was foremost in the minds of the parents who sent their children to the crèche. Because the volunteer teachers were young women, some of whom did not, at the time, have their own children, the older mothers and grandmothers were very sceptical of the young teachers' ability to properly take care of the children in their care. However, as acute as tensions were around this theme of safekeeping, they lessened considerably as, concurrently with the training of the teachers in aspects of early childhood development and education, ECD orientation sessions were presented to the parents.

\section{Scarcity as a dominant discourse of the people of Mogwase}

A community member from Mogwase stated the following:

'Life is hard in Mogwase, we live by making plans and sometimes even those plans dry up.' (2011)

For people who live in poverty, with few resources, both material and otherwise, their experience of any situation is often one of scarcity. In Mogwase, interestingly, the discourse reflected each one of the three definitions of poverty as set out by Wagle (2002). These are material deprivation, capabilities poverty and social and political exclusion and, as reiterated by Narayan et al. (2000:2), a lack of physical, social, environmental, political, educational and psychological resources. The experience of the poor, according to these authors, is mainly one of powerlessness. This was evident in Mogwase where a view of a scarcity of monetary resources led to members of the community lashing out, in some cases with physical violence, at the teachers who had suddenly, through their earning of a small stipend, become top earners in the settlement. Thus, the socially constructed discourse of what counts as fiscal resources had entered the education of young children.

This, according to Casper (2011), is not unusual, especially if it is augmented by a concurrent discourse of scarcity with regard to knowledge and trust. Indeed, in Mogwase, such a discourse permeates the early comments made by parents expressing their dissatisfaction with the volunteer teachers' performance at the crèche, for example, one parent at a meeting said: 'They (the teachers) know nothing about looking after children' while another emphasised: 'Yes, we cannot trust them with our children'. Interestingly, the teachers themselves expressed their own insecurities around their perceived lack of knowledge of early childhood education practice when talking about their work. It is indicative of the progress made in the development of this ECD programme when, towards the end of the research period, the parents, teachers and community leader talk about the teachers in terms of having gained knowledge. Teachers indicate that 'before (the programme) we knew nothing' but that with the intervention of the teacher trainer they 'had learnt to work with children'. A community member describes the centre as 'a place of light, where everyone comes to learn' and parents express their belief that 'the children learn new things, things that will help them at school, (things) that they cannot learn at home'. Thus, across the time span from initiation to the end of the study, there was a notable shift in the perceptions of the community members, as reflected in their discourse from a perceived lack of ownership to a greater sense of agency and ownership of their new educational institution.

\section{Tensions between stakeholders - enabling change}

A teacher trainer from Mogwase stated the following:

'On my new days (as teacher trainer) - it was not easy. Teachers were angry. It was like (they thought) I was coming to boss them of rule them or take their job.' (2012)

The process of implementation of this early childhood intervention sparked considerable tension and conflict within the internal structure of the community and among the different groups who participated in the process of programme development at Mogwase. Firstly, the pressures to develop an ECD curriculum and teacher training programme as conceptualised differently, and indeed dichotomously, by the external development agents and the community, presented great challenges to all role players in the process.

Secondly, a parity of benefit, as conceptualised by Garvey and Newell (2005), soon became apparent as some members of the community, particularly the volunteer teachers, who were getting a small stipend for their work, were perceived to benefit more from the intervention than others. Incidents of physical violence against the teachers, by members of the community, and even by members of the community steering committee, bear testimony to these acute tensions. As was mentioned earlier on, this intervention was externally initiated and did not come about as a result of the community's experience and expression of a need for an early childhood intervention. The danger herein lies in the expectations communities have of social development projects in improving their situation (Eweje 2006). In this community, however, the causal relationship between the intervention and an improved future situation was unclear, and it is possible that members of the community thought that there were much better ways for the donor funder to have spent their money than on early childhood education.

Thirdly, this intervention challenged the status quo of perceived power within the community. Young women, some of whom had by then not had children of their own, 
had suddenly gained the status of 'teachers'. Moreover, by doing 'something that any mother or grandmother could do for a child' (Van der Vyver 2012), they had become top earners within the community. The new social institution, which was fast developing its own management processes and structures, was also impinging on the social 'space' of other, more established structures, such as the community steering committee, who now had to call a meeting with the crèche steering committee whenever they wanted to voice their opinion or suggest a different course of action.

At the onset of the process, and indeed for a while to come, the various expectations of all parties concerned largely remained unmet as everyone grappled with the veritable tidal wave of change that was caused by the actions and reactions of the various role players within the system. It took time for the process to reach a point of relative equilibrium, and even then, often, these 'points of balance' were short lived as new issues created new dynamics within the situation, which had to be handled in ever new ways. But as time went on, the participants came to see that every perceived crisis that arose could be dealt with by a collaborative process of 'teasing it out' until a workable solution was found and implemented and eventually reviewed for whether or not it actually enhanced the working of the ECD centre.

Finally, the introduction of a new social institution, such as an early childhood education centre, might amplify already existing tensions within the community and evoke new ones. Existing positions of power might be challenged as some community members assume new roles as, for example, assistant teachers or board members of the centre, whilst longstanding leadership roles, such as for example, that of older men, might become all but redundant in the day-to-day decision-making processes of those participating in the early childhood programme.

I want to argue that although this intervention indeed caused tensions to mount, it were these very tensions which galvanised the different role players into entering the arena of ECD and speaking out on what they believed it meant for their children. It was only in the increased participation in this dialogue that a 'co-constructed generative curriculum' (Pence \& Marfo 2008) was forged - one which used existing knowledge systems from within the community and blended it with what was relevant, in that context, from Western early childhood development thinking. Thus, over time, and despite all the conflict, the preschool became something that united the different groups of people of Mogwase around the mutual cause of developing their children.

\section{Variants in the views of the different stakeholders in the programme and the different voices from within the community - finding equilibrium}

A parent a volunteer and community leader from Mogwase stated the following:
'Children should go to crèche to be looked after and stay safe.' (2010)

'Children should go to crèche to learn respect.' (2011)

'The crèche created jobs for young people in Mogwase, they are able to learn to become teachers at the crèche. That will take them forward in life.' (2011)

External development agents often employ a unitary view of community when thinking about small rural settlement communities (Skogen \& Krange 2003). Societal implementers of development interventions often ignore the existing social stratifications, alliances and power structures within communities (Cleaver 1999), thus assuming a generic 'community' phenomenon that is nearly impossible to find in the reality of the 21st century. For example, the Setswana speaking people of Mogwase defined 'community' variably as: 'Motsana mo lefelong lengwe [a small group of people living in the same place]; dikgatlhêgô tse di tshwanang [values that are the same]; and baagêlani [who have built together]' (Van der Vyver, Mathikge \& Phiri 2010). In public discourse, however, and especially in a scholarly search on the Internet, it is very rare to find any reference to 'rural communities' outside of the context of poverty and the need to address that poverty in some way. In most academic texts on development studies, the term 'rural community' is defined primarily in terms of the difficulties of living in a rural setting (May 2000).

Also, what external societal development agents mean by terms such as 'development' or 'participation' might be inconsistent with what the community for which the 'participatory development intervention' is intended, understands it to be. As Cleaver (1999:597) highlights in his criticism of the unquestioning acceptance of participatory methods as the best approach to community development pointing to the lack of large-scale evidence and the disparity between 'participation' and the cost-and-time constraints of funded projects, which, he claims, aim to meet logistic rather than strategic needs and favours instrumentality over empowerment.

Indeed, at Mogwase, the dissimilitude between the aims of the corporate donor funder; the educational development of the children and teachers as envisaged by the project manager and scholar of education (myself); and the various groups within the settlement, parents, volunteer teachers, leadership structures, was starkly evident from the beginning. These incongruities surfaced in how different individuals and groups talked about their expectations of the programme, how they viewed the roles of the different stakeholders and how they experienced the different relationships that came about as a result of the ECD centre in their midst. As Sergiovanni (1994) suggests, schools are about relationships and should be viewed first and foremost as communities of different people and the early development of children in rural settlements and the effectiveness with which early childhood education interventions are implemented in these locales depend on the communities understanding and support (Ngobese 2006). 
Still, despite these considerations of the community as consisting of various groups that might have variable views and perceptions of different aspects of society, in smaller rural communities, stronger centrifugal forces are at work, values are more homogenous and local power structures and taboos hold more sway than what is the case at, for example, urban centres where parents are more independent, simply drop their children off at the door and pick them up after the day. At rural settlements, the implementation of an early childhood development programme is not something that only happens to the children of the community. Instead, the various aspects of such a programme might be strongly interlinked and interrelated with other social processes, structures and values.

At Mogwase, local perceptions of childcare and early education certainly influenced the development of the curriculum there. While the teachers, at least at first, perceived their own role to be that of safe keeper and child minder, parents felt that the teachers had to 'teach the children to write their names' and 'prepare them for school' in addition to keeping them safe and out of danger.

The implementation of an early childhood programme at settlements such as Mogwase cannot be viewed as a one-off event but is a process that happens over time. The role players in such a process need be change their opinions and their behaviour so that these become more closely aligned with an envisaged positive educational outcome for the children for whom the intervention is intended. Whereas at first, the employment of young mothers from the community as ECD workers challenged the position of relative power and wisdom with regard to early childcare of the older matriarchs, as all concerned were being encouraged to voice their views and as everyone came to participate in the ECD orientation sessions and in working towards workable solutions for the centre, these very same women, towards the end of the study, described the crèche in terms of the benefits it brought to the children with regard to school readiness and social skills gained. The young mothers, who initially felt pressurised and anxious at the prospect of entrusting other young women with the safety of their children, later on described the changes brought about in their own lives as a result of the intervention in terms of greater freedom to pursue household, leisure or income-generating activities during the day. And the development agents, who at first used their position of relative power as the representatives of the corporate donor funders, came to understand that better outcomes and greater strides were made towards effective delivery of early childhood education and care through participatory methods that encouraged all role players to find and use their voice in finding 'the way that works for the children of Mogwase' (Community leader, Mogwase, 2012).

\section{The map is not the terrain for early childhood educators working in rural contexts}

A volunteer teacher from Mogwase stated the following:

'It is difficult to work with other people's children. When a child gets hurt ... the parents just fight (with one), they do not ask nicely.' (2011)
Living and working in rural contexts is challenging. Obstacles that might have to be surmounted by educators in rural areas in their quest for effective education delivery include poverty, reliance on subsistence livelihoods, a lack of infrastructure, low education and skills levels and a shortage of jobs (Ngobese 2006). Moreover, teachers might have to contend with a shortage of education resources, overfull centres and high caregiver-child ratios (Grey 2008). ECD practitioners in South Africa, as elsewhere in the world, have historically enjoyed a very low status (Biersteker 2010). This larger issue is reflected in Mogwase, where the young volunteer teachers started their careers as ECD educators from a position of relative and perceived powerlessness in terms of agency over the trajectory of the programme and their role in it. Over time though, and through the employment of PAR as methodology, their active participation in the process increased, as they gained knowledge, experience and confidence in their roles as educators. They started negotiating the terms of the programme and voiced their opinion in a discourse that reflected, increasingly, their professional development as teachers. Concurrently with this, parent's knowledge of ECD and of the role of the ECD teacher in their children's education increased through their attendance of the parent orientation programme and therefore the considerable social pressure they had at first exerted on the teachers eased off a little. This change in attitude of the parents towards the teachers is evident in the response of a mother who had, at first, complained that her 4-year-old was unable to read and write after attending the centre for 6 months, but who, towards the end of the study, expressed her satisfaction with her son's progress in terms of social skills gained at the centre: 'My child has learnt to communicate with kids and teachers'.

Teachers in this community, as in many others, conduct their activities from a strong sense of communality and experienced their involvement at the centre as a vocation: 'ke pitso' - 'it is a calling'. This, they felt, especially towards the end of the study, had proved to have been a strong motivator for them to keep on track despite the tensions that they had to manage and process during their training (Van der Vyver 2012). Also, active participation by educators in curriculum development has been found by Mashatini (2005) to help the development of teachers' sense of self-empowerment. Teachers who have a say in the development of the education programme that they are expected to carry out experience their work as positive and personally fulfilling, which help them to overcome challenges at work (2005). This resonates with the organic nature of curriculum development (Henning 2010), in PAR mode, in this settlement - because the teachers reflect the community's values and issues and therefore more closely align the content of the curriculum, and how it is presented to the children, to the actual context and needs of the situation within which the ECD programme is situated (Van der Vyver 2012).

Teachers' experience and their training should be closely aligned to curriculum development (Rinaldo 2005). Although these volunteer educators did not receive any formal training or qualification, they reported to have experienced considerable 
professional growth through their participation in the development of the programme. This is also reflected in the discourse of the teachers towards the end of the study when they spoke about their work in terms of following a 'daily and weekly schedule', 'lesson plans' and voiced their opinion on educational issues such as language of instruction and classroom practice.

\section{The crèche (curriculum) as a societal intervention}

According to a community leader the:

'(Name of corporate donor funder) helped us a lot by giving us a crèche. The other crèches [in the area] are far away and we do not have money to pay for them.' (Mogwase, 2011)

There exists a fair body of criticism in development and education literature of development efforts by external agents with the aim of benefiting a recipient group of people (Hope \& Timmel 1995; Liepins 2000). Kretzman and McKnight (1993) claim that the result of such externally initiated programmes are often counter-development and that they lead to greater dependency on such projects by the communities they aim to serve. Indeed, at Mogwase, by the time this particular development project started, several failed projects had already previously been implemented and abandoned by government thus leaving the people of the settlement wary of outsiders promising them solutions (Van der Vyver 2008). At Mogwase, however, the process of implementation of the preschool, through PAR, seems to have been successful. I suggest that this is because, in this particular instance, the following things happened. Firstly, the large corporate donor funder was flexible enough in its understanding of the dynamics of project implementation at this site to accept that societal interventions by external agents do not follow an algorithmic input-output pattern in which the recipient group, in this case the children, their parents and the teachers at the preschool, does not simply comply to playing along in the formulaic efforts, by others, to 'uplift' them. Instead, in this instance, the corporate trusted the on-site development practitioners enough to allow a certain context-bound flexibility around the time frame and nature of the expected educational outcomes. Secondly, the on-site development practitioners were willing to change their perceptions of their role in the community's processes and to come to new and often unexpected understandings of what ECD, teacher training and curriculum development might mean for this specific group of people at this particular site at that point in time. Thirdly, despite the fact that the community, as a heterogeneous collection of interest groups and individuals, at first constituted a vortex of dichotomous intentions towards the introduction of an early childhood development as a social process, they did, by degrees and through a shift in their paradigm, take ownership of the preschool as their own intervention.

\section{An organic process of curriculum development - using PAR to 'grow' a context-specific curriculum for the people of Mogwase}

According to a parent from Mogwase the:
'Parents complain about the teachers, and then there is a crèche meeting. Then they talk about what bothers them. But at the crèche my child never had a problem.' (2011)

Although this ECD intervention was initiated by outside forces, which caused considerable disequilibrium within the ranks of the role players in the situation, over time the communal will of all the participants united towards the common goal of finding practical solutions to a practical problem in the real world (Van der Vyver 2012). As proposed by Higgs and Smith in their discussion on critical theory (2006:71), social transformation occurs through 'praxis', which means 'theory in practice'. This educational process was about development practice and the practice moreover, of the development of a context-specific curriculum through the empowerment of lay teachers and semi-literate parents so that they were eventually able to take ownership of the preschool in their community. Towards this end, PAR emerged from the participants' growing awareness of their different experiences and the need to find a forum from which all concerned could voice their views and make decisions in order to adapt to their changing situation (Foster-Fisman et al. 2001). This collaboration around a common cause requires planning, communal action and change, adapting to new circumstances and thinking in new ways (Roussos \& Fawcett 2000). In the case of the preschool at Mogwase, the conflicting views caused by the insertion of this preschool in the reality of this community lead the participants and the researcher towards PAR as both research methodology and curriculum development tool (Van der Vyver 2012).

There are several reasons why PAR has been such an effective instrument in the establishment of a preschool programme at Mogwase. Firstly, PAR constitutes action research in action because it helps the practitioner(s) - in this case the development practitioners, the teachers, the parents and the various power structures within the community - explore their situation and ask questions about their actions and what motivates them to act in a certain way (McNiff 2002). PAR is secondly a way to collaboratively create new knowledge, through research and reflexivity, and in doing so encourages people to look for and find answers to the challenges they face (Fals-Borda 2001). Through PAR, people can gain enough transformational momentum to develop new socio-political thought processes (Fals-Borda \& Rahman 1991). Within the arena of ECD at Mogwase, for example, participants from all the various groups came to a new understanding of what early childhood education delivery entails within that context. Finally, PAR enables its users to fuse different kinds of knowledge, for example, their contextual knowledge, unconscious knowledge, practical knowledge and discursive knowledge into a 'new' knowledge with utility value that can be applied to a specific situation (Beukema \& Petersen 2007). This happened in Mogwase as the different stakeholders contributed their various 'knowings', gained from the different spheres of their lived lives, to organically generate an understanding of what would be of utility value for the preschool community at Mogwase. 


\section{Towards a more encompassing view of early childhood development}

It is possible to develop a context-specific early childhood curriculum, especially at rural sites like Mogwase, provided that the implementers of such a programme take into account the specific context of the site and the community the programme is intended for. In the words of Fischman and Tefara (2014), when talking about research, I want to suggest that instead of going about curriculum design in an ivory toweresque way, perhaps we need to employ more usable knowledge mobilisation strategies' and make use of 'multidimensional, interactive strategies' in order to ensure more flexible ECD curricula that will be more closely aligned with the vast diversity of situations within which early childhood development and education take place in the country.

On this view, I argue that perceptions about curriculum development, especially for ECD, needs to come free of the formulaic and monotypic view that any single, pre-planned curriculum could possibly address the myriad, often paradoxical issues that interface life for the people in rural settlements in South Africa today. Furthermore, I contend that what is important in any curriculum is not so much its content but how and how effectively it is implemented in diverse and often challenging contexts in South Africa. Contexts are about people living real lives in specific situations. Early childhood education development should happen in ways that take these lives, the day-to-day realities of the people living in a certain place at a certain time, into account. ECD curriculum development cannot be separated from the action of its implementation. To exemplify the notion of ongoing action towards a specific objective, De Beer and Henning (2011) point out that the Russian word for activity is not directly translatable into English and that the German translation Tätigkeit or 'doingness' explains the notion of ongoing engagement in a programme of action towards a specific objective, with a specific motivation, and envisages a specific outcome. I believe that it is only in this 'doingness' (2011), the implementing-as-action, that it is possible to establish what works and what does not work as ECD practice at any specific site. Furthermore, I want to suggest that curriculum implementation should not be seen as a single event or an algorithmic series of steps that need to be taken and then ticked off on a to-do-list, but that it is a process that emerges from a specific history of the place and the people that it is intended for and that its very process and progression changes the fabric of reality for the people at a given site.

The literal meaning of the word context is 'that which is braided together' (Kincheloe \& Steinberg 1993). The interactions between participants in this intervention and the aspects of life which constitutes the context of places like Mogwase, through PAR, reinforces the meaning of 'curriculum' as a part of the road of life. Thus, for the purposes of developing this programme, which is ongoing even today, to the people involved there, 'curriculum' means: 'that which emerges as reality, that which is tried and works, and that which is tried and found wanting and which will be changed according to what is required of the context or the situation'.

\section{Conclusion}

The emerging ECD programme at Mogwase came about in an organic way - a process during which, what germinates in the virgin soil of this emerging programme will be nurtured, what grows will be tended with care, what does not work will be pruned off and discarded and in the end, hopefully, some useful seeds of knowledge could be harvested for future use in similar settings.

Firstly, curriculum implementers need to be aware and remain aware of the intricate interrelatedness of aspects of education delivery at rural sites; teachers, school, community and setting - that these are so closely knitted together that what impacts upon one, impacts upon the whole and in ways that might be hard to predict or prepare for. Moreover, that whatever course of action is decided upon will impact upon children whose educational journey could be either set on a stable course or derailed by interventions that are implemented in a careless way.

Secondly, that as unlikely as it may have appeared at the outset, the implementation of this society-initiated ECD intervention was made successful through a reflective process of participation and collaboration, which resulted, by and by, in the intervention being ultimately owned by the community for which it was intended. This was achieved because the tensions that were activated during the process, as uncomfortable as they felt to the various participants, were harnessed and used as catalyst for the change that took place in this community during this project.

Thirdly, as far as teaching practice is concerned, the contextspecific findings of this study indicate that teacher education programmes at higher education institutions could perhaps do more to integrate the different realities within which ECD delivery often takes place into their teacher educator programmes. Teacher education students should perhaps be given the opportunity to visit diverse ECD delivery sites, such as those facilities operating from township shacks or rural villages, like the one in this study, in order to broaden their view of education delivery. It could add value to teacher education if information about early childhood and about the different contexts in which children grow up in South Africa is integrated into foundation phase teacher education programmes. This could do a lot to dispense some of the 'one-size-fits-all' education practice myths that often persist in training programmes that are developed from Western early childhood knowledge systems.

Finally, because historically, in South Africa, ECD implementation and training has been the domain of NGOs, the investigation of such an intervention usually requires, by the funding agent, the evaluation of tangible evidence of deliverables and the careful measuring of cost expenditure against outcomes. In my opinion, the outcomes or possible gains brought about by an intervention that has as its aim the early cognitive, socio-emotional and physical development of human beings cannot be measured according to the criteria of a 
production line. Furthermore, the unintended (by the funder) benefits of such an intervention in terms of human and community development would require a much broader view of evaluation than what can be achieved through the project evaluation approach. Indeed, I would argue that it would require an extensive and intensive longitudinal study to truly measure the impact of an early childhood education intervention in a resource-poor rural situation. Furthermore, if academic research were to become the norm as part of the planning of community ECD interventions, it seems unlikely that corporate donor funders would so readily expend resources on projects that, experience has shown, often fail because of a lack of rigorous in-depth research before implementation.

Conducting an inquiry within an ECD situation that is funded by external agents implies that there are certain restrictions within which actions and events take place. The fact that this intervention was funded by a corporate donor funder meant that, despite the fact that the development of the curriculum and the training of the teachers took place in PAR mode, the staff and other role players at this preschool had to adhere to certain strictures. Schedules, budgets and donor policy restrictions all play a role and could add to the potential tension between role players. The time afforded for this programme to be established was a factor in the success of the development of this ECD centre and one that is often not considered when the need for measuring outcomes against time is a priority on the social responsibility agenda of a corporate donor funder. Interventions such as training and curriculum development take time and furthermore, PAR implies the building of trusting relationships that can only be forged over time.

Bearing in mind the limitations of this type of study, and also that the inquiry focused on only one phase of a potentially more extensive PAR study, the process of the study and the findings have a message: participatory work can happen in interventions (both research and development) that has been initiated from outside, by societal forces, with the proviso that members' voices are recognised and considered. I conclude the study with a call for a deeper understanding of the interplay between different structures of society and community in development work, specifically as it pertains to the teachers and the beginnings of an ECD curriculum within the emergent education structure in rural settlements.

\section{Acknowledgements}

In the second phase of the study that is reported in this article, I conducted a study towards an M.Ed degree, and I was a bursary holder in the DHET/EU Programme of Research at the University of Johannesburg. I thank Prof. Elizabeth Henning for her help in writing this article.

\section{Competing interests}

The author declares that she has no financial or personal relationships which may have inappropriately influenced her in writing this article.

\section{References}

Aber, J.L., Bennet, N.G., Conley, D.C. \& Li, J., 1997, 'The effects of poverty on child health and development', Annual Reviews Public Health 18(1997), 463-483. http://dx.doi.org/10.1146/annurev.publhealth.18.1.463

Aliber, M., 2003, 'Chronic poverty in South Africa: Incidence, causes and policies', World Development 31(3), 473-490. http://dx.doi.org/10.1016/S0305-750X(02)00219-X

Anderson, L.M., Shinn, C., Fullilove, M.T., Scrimshaw, S.C., Fielding, J.E., Normand, J. et al., 2003, 'The effectiveness of early childhood development programs: A systematic review', American Journal of Preventative Medicine 24(3S), 32-46. http://dx.doi.org/10.1016/S0749-3797(02)00655-4

Atmore, E., 1994, 'Multicultural education, anti-racist practice and early childhood education in the South African context', in L. Le Roux (ed.), The black child in crisis. A socio-educational perspective, vol. 2, J.L. van Schaik Publishers, Pretoria.

Atmore, E., van Niekerk, L. \& Ashley-Cooper, M., 2012, 'Challenges facing the early childhood development sector in South Africa', South African Journal of Childhood Education 2(1), 120-139.

Beukema, L. \& Peterson, N., 2007, 'Participatory Action Research', Presentation to SANPAD Cohort.

Biersteker, L., 2001, Early Childhood Development: A review of public policy and funding, Study commissioned by the Children's Budget Unit of Idasa (n.p.): IDASA.

Biersteker, L., 2010, 'Scaling-up early child development in South Africa: Introducing a reception year (grade R) for children aged five years as the first year of schooling', Wolfensohn Centre for Development. Working paper 17, April. Brookings Institution Press, Washington DC.

Biersteker, L. \& Dawes, A., 2008, 'Early childhood development. Chapter 9', in A. Kraak, K. Press (eds.), Human resources development review, HSRC PRESS, Cape Town.

Casper, V., 2011, ECD lecture at the centre for education practice research, University of Johannesburg, Johannesburg.

Chambers, B., Cheung, A., Slavin, R.E., Smith, D. \& Laurenzano, M., 2010, Effective early childhood education programmes: A systematic review, Johns Hopkins University, Center for Research and Reform in Education, Baltimore, MD.

Children's Institute, University of Cape Town. 2012. 'Children count: Statistics on children in South Africa', viewed 25 September 2014, from http://www. childrencount.ci.org.za/domain.php?id=2

Cleaver, F., 1999, 'Paradoxes of participation: Questioning participatory approached to development', Journal of International Development 11(1999), 597-612. http:// dx.doi.org/10.1002/(SICI)1099-1328(199906)11:4<597::AID-JID610>3.0.CO;2-Q

Dearing, E., Berry, D. \& Zaslow, M., 2006, 'Poverty during early childhood', in K. McCartney, \& D. Phillips (eds.), Blackwell handbook of early childhood development, Blackwell Publishing, Oxford.

De Beer, J. \& Henning, E., 2011, 'Retreating to a Vygotskian stage, where pre-service teachers play out social, "dramatical collisions"', Acta Academica 43(3), 203-228.

Edwards, C.P., 2002, 'Three approaches from Europe: Waldorf, Montessori and Regio Emilia', Early Childhood Research and Practice 4(1), 2002, viewed 5 October 2011 , from http://ecrp.uiuc.edu/v4n1/edwards.htm

EFA Global Monitoring Report, 2006, The Quality Imperative, UNESCO Publishing, Paris. EFA Global Monitoring Report, 2007, Strong foundations, UNESCO Publishing, Paris.

EFA Global Monitoring Report, 2010, Literacy for life, UNESCO Publishing, Paris.

Eweje, G., 2006, 'The role of MNE's in community development initiatives in developing countries: Corporate social responsibility at work in Nigeria and South Africa' Businessand Society 45(2), 93-129. http://dx.doi.org/10.1177/0007650305285394

Fals-Borda, O. \& Rahman, M.A., 1991, Action and knowledge: Breaking the monopoly with participatory action research, Apex Press, New York.

Fals-Borda, O., 2001, 'Participatory (action) research in social theory: origins and challenges', in P. Reason \& H. Bradbury (eds.), Handbook of action research. Participative inquiry and practice, Sage, London.

Fischman, G. \& Tefara, A., 2014, If research is not used, does it exist? Teachers college record-17 June 2014, viewed 20 June 2014, from http://w.w.w.tcrecord.org

Foster-Fishman, P.G., Berkowitz, S.L., Lounsbury, D.W., Jacobson, S. \& Allen, N.A., 2001, 'Building collaborative capacity in community coalitions: A review and integrative framework', American Journal of Psychology 29(2), 241-261. http:// dx.doi.org/10.1023/a:1010378613583

Garvey, N. \& Newell, P., 2005, 'Corporate accountability to the poor? Assessing the effectiveness of community-based strategies', Development in Practice 15(3), 389-404. http://dx.doi.org/10.1080/09614520500075763

Grey, M.J., 2008, 'An investigation of the programmes and equipment used by caregivers and day mothers for the age group 0-36 months in the Limpopo Province, South Africa', Master's thesis, Wits University, Johannesburg, South Africa, viewed 12 November 2011, from http://wiredspace.wits.ac.za/bitstream/ Africa, viewed 12 November 2011, from http://wiredspace.wits.ac.za/bitstream/ 7(dees\%20Version).pdf?sequence $=4$

Higgs, P. \& Smith, J., 2006, Rethinking truth, 2nd edn., Juta and Company Ltd, Cape Town.

Hope, A. \& Timmel, S., 1995, Training for transformation: Book 1, ITDG Publishing, London.

Human Science Research Council (Child, Youth, Family and Social Development) \& Early Resource Learning Unit. (2010), Final Report - Western Cape Department of Social Development 2009 Audit of early childhood development facility quality, Government Printers, Pretoria.

Kincheloe, J.L. \& Steinberg, S.R., 1993, 'A tentative description of post-formal thinking: The critical confrontation with cognitive theory', Harvard Educational Review 63(3), 296-320. http://dx.doi.org/10.17763/haer.63.3.h423221226v18648 
Kretzman, J.P. \& McKnight, J.L., 1993, Building community from the inside out: a path towards finding and mobilizing a community's assets, The Asset-based Community
Development Institute. Institute for Policy Research, Northwestern University, Evanston, IL.

Liepins, R., 2000, 'New Energies for an old idea: Reworking approaches to 'community' in contemporary rural studies', Journal of Rural Studies 16(2000), 23-35. http:// dx.doi.org/10.1016/S0743-0167(99)00042-X

Loomis, C. \& Akkari, A., 2014, 'The impact of formal early childhood care and education on the cognitive development and academic potential of children in Madagascar: A literature review', Journal of Innovation in Psychology, Education and Didactics 18(1), 7-24.

Mashatini, N.F., 2005, 'Self-empowerment for teachers as an aspect of curriculum development', Unpublished master's thesis, University of Johannesburg, South Africa.

May, J., 2000, 'The structure and composition of rural poverty and livelihoods in South Africa', in B. Cousins (ed.), At the crossroads: Land and Agrarian Reform in South Africa: Into the 21st Century, PLAAS, Bellville.

McNiff, J., 2002, Action research for professional development. Concise advise for new action researchers, 3rd edn., viewed 29 June 2011, from http://www. actionresearch.net

Narayan, D., Chambers, R., Shah, M.K. \& Petesch, P., 2000, Voices of the poor crying out for change, Oxford University Press, New York.

Ngobese, Z.X., 2006, 'Exploring the problems of teachers and their teaching in farm schools', Unpublished master's thesis, University of Johannesburg, Johannesburg South Africa.

Nores, M. \& Barnett, W.S., 2009, 'Benefits of early childhood interventions across the world: (Under) Investing in the very young', Economics of Education Review 29(2010), 271-282. http://dx.doi.org/10.1016/j.econedurev.2009.09.001

Nsamenang, A.B., 2007, 'A critical peek at early childhood care and education in Africa', Child Health and Education 1(1), 1-12.

Pence, A.R. \& Marfo, K., 2008, 'Early childhood development in Africa: Interrogating constraints of prevailing knowledge bases', International Journal of Psychology 2008(i), 1-10.
Rinaldo, V., 2005, 'Today's practitioner is both qualitative and quantitative researcher', The High School Journal 89(1), 72-77. http://dx.doi.org/10.1353/hsj.2005.0017 Roussos, S.T. \& Fawcett, S.B., 2000, 'A review of collaborative partnerships as a
strategy for improving community health', Annual Review Public Health 21(2000), 369-402. http://dx.doi.org/10.1146/annurev.publhealth.21.1.369

Sergiovanni, T., 1994, 'Building communities in schools', [Abstract] Harvard Educational Review (Winter 1996), viewed 15 November 2011, from http://www. hepg.org/her/abstract/25/

Skogen, K. \& Krange, O., 2003, 'A wolf at the gate: the anti-carnivore alliance and the symbolic construction of community', Sociologia Ruralis 43(3), 309-325. http:// dx.doi.org/10.1111/1467-9523.00247

South Africa. Department of Basic Education, 2010a, Action Plan to 2014: Towards the realization of Schooling 2025, viewed December 2011, from http://www. education.gov.za/Curriculum/ActionPlanto2014/tabid/418/Default.aspx

South Africa. Department of Basic Education, 2010b, Education statistics in South Africa, 2009, Formeset Print (Pty) Ltd, Tshwane.

South Africa. Department of Basic Education, 2011, Strategic Plan 2011-2014, viewed 15 December 2011, from www.gov.co.za

South Africa. Department of Basic Education, 2013, Education statistics in South Africa, 2011, Formeset Print (Pty) Ltd, Tshwane.

Summers, G.F., 1986, 'Rural community development', Annual Review of Sociology 12(1986), 347-371, viewed 29 November 2011, from http://www.jstor.org/stable/2083207

Van der Vyver, S., 2008, 'Baseline assessment of the Mogwase Project', Unpublished baseline evaluation report for SABMiller Ltd., Johannesburg.

Van der Vyver, S., 2012, 'An early childhood development programme in a rura settlement community', Unpublished Master's thesis, University of Johannesburg, Johannesburg, South Africa.

Van der Vyver, S., Mathikge, P. \& Phiri, S., 2010, 'The meaning of 'rural' and 'community' in a Setswana speaking rural community in South Africa', Unpublished monitoring evaluation report for Village Power Community Development Projects, Magaliesburg, South Africa.

Wagle, U., 2002, 'Rethinking poverty: Definition and measurement', International Socia Science Journal 54(171), 155-165. http://dx.doi.org/10.1111/1468-2451.00366 